\title{
Drug-eluting stents versus coronary artery bypass graft surgery in left main coronary artery disease: A meta-analysis of early outcomes from randomized and nonrandomized studies
}

\author{
Christopher Cao, MBBS, BSc (Med), ${ }^{\text {a,b }}$ Con Manganas, MBBS, ${ }^{\mathrm{b}}$ Paul Bannon, MBBS, PhD, ${ }^{\mathrm{a}}$ \\ Michael Vallely, MBBS, $\mathrm{PhD},{ }^{\mathrm{a}}$ and Tristan D. Yan, $\mathrm{MD}, \mathrm{PhD}^{\mathrm{a}}$
}

Objective: The present meta-analysis aimed to compare the short-term safety and efficacy of drug-eluting stents and coronary artery bypass graft surgery for patients with left main coronary artery disease.

\begin{abstract}
Methods: Fourteen relevant studies were identified from 5 electronic databases. End points included mortality, stroke, myocardial infarction, repeat revascularization, and major adverse cardiac and cerebrovascular events.

Results: Results indicate that all-cause mortality was similar between drug-eluting stents and coronary artery bypass grafting at 30 days and at follow-up beyond 1 year. Likewise, the incidence of myocardial infarction was similar between drug-eluting stents and coronary artery bypass grafting at 12 months and at follow-up beyond 1 year. However, drug-eluting stents were associated with a lower incidence of all-cause mortality at 12 months and a higher incidence of myocardial infarction at 30 days compared with coronary artery bypass grafting. Drug-eluting stents were consistently associated with a higher incidence of repeat revascularization, whereas coronary artery bypass grafting had a higher incidence of stroke. The incidence of major adverse cardiac and cerebrovascular events was similar between the 2 groups at 30 days but higher for drug-eluting stents at 12 months and beyond.
\end{abstract}

Conclusions: Patients treated by drug-eluting stents in randomized controlled trials and observational studies in the current literature are often a preselected subgroup with less complex lesions compared with the overall target population. Results drawn from these studies should be viewed with caution. Coronary artery bypass grafting is associated with a lower incidence of major adverse cardiac and cerebrovascular events at 1 year and beyond, and thus should be regarded as the standard of treatment. However, drug-eluting stents may have a role for selected patients with percutaneously amenable left main disease who are poor surgical candidates. (J Thorac Cardiovasc Surg 2013;145:738-47)

Earn CME credits at

http://cme.ctsnetjournals.org

Left main coronary artery disease (LMCAD) is defined as a greater than $50 \%$ narrowing of the left main coronary artery and is found in approximately $5 \%$ of all patients who undergo angiography. ${ }^{1}$ Without revascularization, patients with LMCAD have a relatively poor prognosis, with 3 -year survival as low as $34 \%$. $^{2}$ Previous studies have demonstrated a clear survival benefit from revascularization over medical management. ${ }^{2,3}$ Because of the anatomic

From The Baird Institute for Applied Heart and Lung Surgical Research, ${ }^{\text {a }}$ Sydney, Australia; and the Department of Cardiothoracic Surgery, ${ }^{\mathrm{b}}$ St George Hospital, Sydney, Australia.

Disclosures: Authors have nothing to disclose with regard to commercial support. Received for publication Sept 29, 2011; revisions received Jan 15, 2012; accepted for publication Feb 3, 2012; available ahead of print March 12, 2012.

Address for reprints: Tristan D. Yan, MD, PhD, The Baird Institute for Applied Heart and Lung Surgical Research, Sydney, Australia (E-mail: tristan.yan@ hotmail.com). 0022-5223/\$36.00

Copyright (C) 2013 by The American Association for Thoracic Surgery doi: $10.1016 /$ j.jtcvs.2012.02.004 complexity and unfavorable characteristics often associated with left main coronary artery lesions, percutaneous coronary intervention (PCI) has been traditionally deferred in preference for coronary artery bypass grafting (CABG). ${ }^{4}$ However, with the evolution of drug-eluting stents (DES) in recent years, there has been a renewed interest in expanding the indication for PCI in patients with LMCAD. ${ }^{5}$ This shift in paradigm was reflected in recent guidelines that recommended consideration of PCI for selected patients with low risk of PCI-related complications and increased risk of surgical complications. ${ }^{6}$ The recent European Society of Cardiology and the European Association for Cardiothoracic Surgery guidelines on myocardial revascularization made level IA recommendations for $\mathrm{CABG}$ in all patients with $\mathrm{LMCAD}$, whereas PCI was only recommended for selected patients with less complex disease based on level II or III evidence. ${ }^{7}$

Despite encouraging results for DES from relatively small observational studies with limited follow-up, there was a lack of robust clinical data to compare DES with CABG in patients with LMCAD. ${ }^{8}$ In view of this, a number of randomized controlled trials have recently been published to compare these 2 revascularization techniques. ${ }^{9-12}$ 


\section{Abbreviations and Acronyms \\ $\mathrm{CABG}=$ coronary artery bypass grafting \\ CI $=$ confidence interval \\ DES = drug-eluting stent \\ LMCAD $=$ left main coronary artery disease \\ MACCE = major adverse cardiac and cerebrovascular events \\ PCI = percutaneous coronary intervention \\ $\mathrm{RR} \quad=$ relative risk \\ SYNTAX $=$ Synergy between Percutaneous \\ Coronary Intervention with Taxus and Cardiac Surgery}

The aim of the present meta-analysis is to assess the shortterm outcomes after DES or CABG for patients with LMCAD by using data from randomized and nonrandomized comparative studies in the current literature. Specific end points include components of major adverse cardiac and cerebrovascular events (MACCE), including mortality, stroke, myocardial infarction, and repeat revascularization.

\section{PATIENTS AND METHODS}

\section{Literature Search Strategy}

Electronic searches were performed using Ovid Medline, Cochrane Central Register of Controlled Trials, Cochrane Database of Systematic Reviews, ACP Journal Club, and Database of Abstracts of Review of Effectiveness from January 2000 to August 2011. To achieve the maximum sensitivity of the search strategy and identify all studies, we combined the terms surgery or coronary artery bypass with angioplasty or stent or percutaneous coronary intervention and left main. The reference lists of all retrieved articles were reviewed for further identification of potentially relevant studies. All relevant articles identified were assessed with application of the inclusion and exclusion criteria.

\section{Selection Criteria}

Eligible comparative studies for the present meta-analysis included those in which patients with angiographically proven LMCAD were treated by DES or CABG. All forms of DES were included, as were patients who underwent off-pump CABG. For studies that included patients with LMCAD as a subset of patients who had other types of coronary artery diseases, results for patients with LMCAD who underwent DES or CABG were extracted when possible. Likewise, studies that included DES as a proportion of patients who underwent PCI were only included if outcomes were available for the DES cohort. When centers have published duplicate trials with accumulating numbers of patients or increased lengths of followup, only the most complete reports were included for qualitative appraisal at each time interval. To maintain the consistency of measured end points, previous guidelines and definitions were used to assess short-term outcomes when applicable. ${ }^{13,14}$ It is acknowledged that patient selection for revascularization varied among institutions and sometimes within an institution at different time periods. All publications were limited to human subjects and in the English language. Abstracts, case reports, conference presentations, editorials, and expert opinions were excluded. Review articles are omitted because of potential publication bias and possible duplication of results. Studies that included fewer than 20 patients or presented data with less than 12 months follow-up were also excluded.

\section{Data Extraction and Critical Appraisal}

All data were extracted from article texts, tables, and figures. When insufficient data were available from publications, corresponding authors were contacted to provide additional records. Two investigators (C.Q.C. and T.D.Y.) independently reviewed each retrieved article. Discrepancies between the 2 reviewers were resolved by discussion and consensus. The final results were reviewed by the senior investigators.

\section{Statistical Analysis}

Meta-analysis was performed by combining the results of reported incidences of mortality, stroke, myocardial infarction, repeat revascularization, and MACCE. The relative risk (RR) was used as a summary statistic. In the present study, both fixed and random effect models were tested. In a fixed effect model, it was assumed that treatment effect in each study was the same, whereas in a random effect model, it was assumed that there were variations between studies and the calculated ratios thus had more conservative value. ${ }^{15}$ Chi-square tests were used to study heterogeneity between trials. $\mathrm{I}^{2}$ statistic was used to estimate the percentage of total variation across studies due to heterogeneity rather than chance. $\mathrm{I}^{2}$ can be calculated as $\mathrm{I}^{2}=100 \% \times(\mathrm{Q}-d f) / \mathrm{Q}$, with $\mathrm{Q}$ defined as Cochrane's heterogeneity statistics and $d f$ defined as degrees of freedom. ${ }^{16} \mathrm{An} \mathrm{I}^{2}$ value greater than $50 \%$ was considered substantial heterogeneity. If there was substantial heterogeneity, the possible clinical and methodological reasons for this were explored qualitatively. In the present meta-analysis, the results using the random effects model were presented to take into account the possible clinical diversity and methodological variation among studies. Specific analyses considering confounding factors were not possible because raw data were not available. All $P$ values were 2-sided. All statistical analysis was conducted with Review Manager Version 5.1.2 (Cochrane Collaboration, Software Update, Oxford, UK).

\section{RESULTS}

\section{Quantity and Quality of Trials}

A total of 1018 references were identified through the 5 electronic database searches. After exclusion of duplicate or irrelevant references, 570 potentially relevant articles were retrieved for more detailed evaluation. After the selection criteria were applied, 16 comparative studies remained for assessment. Manual search of the reference lists did not identify any additional relevant studies. One study was excluded because of duplicating patients at different follow-up periods. One study was excluded because primary outcome data were not available. Of the 14 studies included for final analysis in the present meta-analysis, 3 were from randomized controlled trials and the remainder were from observational studies, as summarized in Table 1.9-12,17-26

In these 14 studies, 5628 patients with LMCAD were compared, including 2490 patients who were treated with DES and 3138 patients who underwent CABG. Baseline characteristics, patient selection, and follow-up periods varied between studies, as summarized in Table 2 .

\section{Assessment of Mortality}

All-cause mortality was not significantly different between DES and CABG at 30 days $(2.3 \%$ vs $4.6 \%$; RR, $0.57 ; 95 \%$ confidence interval $[\mathrm{CI}], 0.22-1.51 ; P=.26$; $\mathrm{I}^{2}=54 \%$ ). At 12 months, DES was found to be associated with a significantly lower all-cause mortality $(3.5 \%$ vs $5.7 \%$; RR, 0.71; 95\% CI, 0.54-0.95; $P=.02 ; \mathrm{I}^{2}=0 \%$ ). 
TABLE 1. Summary of comparative studies included in the present meta-analysis

\begin{tabular}{|c|c|c|c|c|c|c|c|c|}
\hline \multirow[b]{2}{*}{ First author } & \multirow[b]{2}{*}{ Reference no. } & \multirow[b]{2}{*}{ Location } & \multirow[b]{2}{*}{ Study design } & \multirow[b]{2}{*}{ Study period } & \multicolumn{2}{|c|}{ No. of patients } & \multicolumn{2}{|c|}{ Follow-up (mo) } \\
\hline & & & & & DES & CABG & DES & CABG \\
\hline Boudriot & 8 & Leipzig, Germany & $\mathrm{RCT}$ & 2003-2009 & 100 & 101 & & 36 \\
\hline Cheng & 17 & Taiwan, China & OS & $2000-2007$ & 94 & 216 & 16 & 27 \\
\hline Chieffo & 18 & Milan, Italy & OS & 2002-2004 & 107 & 142 & & 62 \\
\hline Ghenim & 19 & Toulouse, France & OS & 2004-2007 & 105 & 106 & & 12 \\
\hline Kang & 20 & Seoul, Korea & OS & 2003-2006 & 205 & 257 & & 34 \\
\hline Kappetein & 10 & US/Europe & Predefined subgroup analysis of RCT & 2005-2007 & 357 & 348 & & 36 \\
\hline Makikallio & 21 & Kajaani, Finland & OS & $2005-2007$ & 49 & 238 & & 12 \\
\hline Palmerini & 22 & Blogna, Italy & OS & 2003-2006 & 98 & 161 & & 24 \\
\hline Park D-W & 23 & Seoul, Korea & OS & $2000-2006$ & 784 & 690 & & 62 \\
\hline Park S-J & 11 & Seoul, Korea & $\mathrm{RCT}$ & 2004-2009 & 300 & 300 & & 24 \\
\hline Sanmartin & 24 & Vigo, Spain & OS & $2000-2005$ & 96 & 245 & 16 & 38 \\
\hline Serruys & 12 & US/Europe & Predefined subgroup analysis of RCT & 2005-2007 & 357 & 348 & & 12 \\
\hline Shimizu & 25 & Tokyo, Japan & OS & 2004-2007 & 64 & 89 & 19 & 26 \\
\hline $\mathrm{Wu}$ & 26 & Beijing, China & OS & 2003-2006 & 131 & 245 & & 48 \\
\hline
\end{tabular}

$D E S$, Drug-eluting stent; $C A B G$, coronary artery bypass grafting; $R C T$, randomized controlled trial; $O S$, observational study.

TABLE 2. Summary of baseline patient characteristics from comparative studies included in the present meta-analysis

\begin{tabular}{|c|c|c|c|c|c|c|c|c|c|c|c|c|}
\hline \multirow[b]{2}{*}{ First author } & \multicolumn{3}{|c|}{ Age, $y$} & \multicolumn{2}{|c|}{ Male } & \multicolumn{3}{|c|}{ Ejection fraction $(\%)$} & ACS & \multicolumn{2}{|c|}{ Diabetes } & \multirow{2}{*}{$\frac{\text { Off-pump }}{\text { CABG }}$} \\
\hline & \multicolumn{2}{|c|}{ DES } & CABG & DES & CABG & \multicolumn{2}{|l|}{ DES } & CABG & DES & DES & CABG & \\
\hline Boudriot & \multicolumn{2}{|c|}{$66^{*}$} & $69^{*}$ & $72 \%$ & $78 \%$ & \multicolumn{2}{|l|}{$65^{*}$} & $65^{*}$ & NR & $40 \%$ & $33 \%$ & $46 \%$ \\
\hline Cheng & \multicolumn{2}{|c|}{$68 \pm 10$} & $67 \pm 9$ & $75 \%$ & $76 \%$ & \multicolumn{2}{|c|}{$56 \pm 17$} & $56 \pm 20$ & $76 \%$ & $35 \%$ & $51 \%$ & $8 \%$ \\
\hline Chieffo & \multicolumn{2}{|c|}{$64 \pm 10$} & $68 \pm 10$ & NR & NR & \multicolumn{2}{|l|}{$52 \pm 10$} & $52 \pm 11$ & NR & $19 \%$ & $23 \%$ & $39 \%$ \\
\hline Ghenim & \multicolumn{2}{|c|}{$81 \pm 3.5$} & $80 \pm 3.5$ & $64 \%$ & $72 \%$ & \multicolumn{2}{|l|}{$26 \% \ddagger$} & $17 \% \ddagger$ & $70 \%$ & $31 \%$ & $24 \%$ & $0 \%$ \\
\hline Kang & \multicolumn{2}{|c|}{$64 \pm 12$} & $66 \pm 10$ & $70 \%$ & $74 \%$ & \multicolumn{2}{|l|}{$56 \pm 12$} & $55 \pm 13$ & $59 \%$ & $38 \%$ & $44 \%$ & $72 \%$ \\
\hline Kappetein $\dagger$ & \multicolumn{2}{|c|}{ NR } & NR & NR & NR & \multicolumn{2}{|l|}{ NR } & NR & NR & NR & NR & NR \\
\hline Makikallio & & \pm 10 & $70 \pm 9$ & $59 \%$ & $80 \%$ & $55 \pm 12$ & & $54 \pm 11$ & $53 \%$ & $20 \%$ & $17 \%$ & $52 \%$ \\
\hline Palmerini & & $1 *$ & $78 *$ & $54 \%$ & $66 \%$ & $50 *$ & & $53^{*}$ & $77 \%$ & $31 \%$ & $26 \%$ & $21 \%$ \\
\hline Park D-W & & \pm 11 & $64 \pm 9$ & $71 \%$ & $72 \%$ & $60 \pm 11$ & & $56 \pm 12$ & $63 \%$ & $32 \%$ & $37 \%$ & $42 \%$ \\
\hline Park S-J & & \pm 10 & $63 \pm 10$ & $76 \%$ & $77 \%$ & $62 \pm 8$ & & $61 \pm 9$ & $47 \%$ & $34 \%$ & $30 \%$ & $64 \%$ \\
\hline Sanmartin & & \pm 13 & $66 \pm 10$ & $81 \%$ & $87 \%$ & $33 \% \ddagger$ & & $24 \% \ddagger$ & $51 \%$ & $19 \%$ & $32 \%$ & NR \\
\hline Shimizu & & & $70 \pm 9$ & $81 \%$ & $85 \%$ & $6 \% \oint$ & & $12 \% \oint$ & $33 \%$ & $65 \%$ & $54 \%$ & $91 \%$ \\
\hline $\mathrm{Wu}$ & & \pm 11 & $64 \pm 9$ & $76 \%$ & $83 \%$ & $60 \pm 12$ & & $59 \pm 12$ & $68 \%$ & $27 \%$ & $29 \%$ & $22 \%$ \\
\hline & & only & $\mathbf{L M}+$ & vessel & $\mathbf{L M}+$ & vessels & $\mathbf{L M}+$ & -3 vessels & SYNT & $X$ score & Eur & score \\
\hline & DES & CABG & DES & CABG & DES & CABG & DES & CABG & DES & CABG & DES & CABG \\
\hline Boudriot & $28 \%$ & $29 \%$ & $35 \%$ & $27 \%$ & $26 \%$ & $28 \%$ & $11 \%$ & $17 \%$ & $24 *$ & $23^{*}$ & $2.4^{*}$ & $2.6^{*}$ \\
\hline Cheng & $3 \%$ & $1 \%$ & $10 \%$ & $4 \%$ & $21 \%$ & $17 \%$ & $66 \% \|$ & $77 \% \|$ & NR & NR & $6.9 \pm 3.5$ & $6.4 \pm 3.3$ \\
\hline Chieffo & NR & NR & NR & NR & NR & NR & NR & NR & $28.8 \pm 10.4$ & $29.4 \pm 5.8$ & $4.4 \pm 3.6$ & $4.3 \pm 3.4$ \\
\hline Ghenim & NR & NR & $31 \%$ & $5 \%$ & $40 \%$ & $13 \%$ & $30 \%$ & $82 \%$ & NR & NR & $8 *$ & $7 *$ \\
\hline Kang & $15 \%$ & $6 \%$ & $32 \%$ & $9 \%$ & $21 \%$ & $25 \%$ & $33 \%$ & $60 \%$ & NR & NR & $4.2 \pm 3.9$ & $5.6 \pm 3.8$ \\
\hline Kappetein $\dagger$ & $12 \%$ & $14 \%$ & $19 \%$ & $20 \%$ & $31 \%$ & $30 \%$ & $38 \%$ & $35 \%$ & NR & NR & NR & NR \\
\hline Makikallio & $69 \%$ & NR & NR & NR & NR & NR & NR & NR & NR & NR & $7.7 \pm 7.5$ & $5.2 \pm 4.4$ \\
\hline Palmerini & NR & NR & NR & NR & NR & NR & NR & NR & NR & NR & $8 *$ & $7 *$ \\
\hline Park D-W & NR & NR & NR & NR & NR & NR & NR & NR & NR & NR & NR & NR \\
\hline Park S-J & $9 \%$ & $11 \%$ & $17 \%$ & $18 \%$ & $34 \%$ & $30 \%$ & $41 \%$ & $41 \%$ & $24.4 \pm 9.4$ & $25.8 \pm 10.5$ & $2.6 \pm 1.8$ & $2.68 \pm 1.9$ \\
\hline Sanmartin & NR & NR & NR & NR & NR & NR & NR & NR & NR & NR & $4.0 \pm 2.5$ & $3.9 \pm 3.0$ \\
\hline Shimizu & $0 \%$ & $1 \%$ & $28 \%$ & $8 \%$ & $23 \%$ & $29 \%$ & $48 \%$ & $62 \%$ & NR & NR & $2.7^{*}$ & $4.9^{*}$ \\
\hline $\mathrm{Wu}$ & $9 \%$ & $3 \%$ & $18 \%$ & $4 \%$ & $38 \%$ & $26 \%$ & $35 \%$ & $67 \%$ & NR & NR & $4.2 \pm 2.7$ & $4.3 \pm 2.4$ \\
\hline
\end{tabular}

$A C S$, Acute coronary syndrome; $D E S$, Drug-eluting stent; $C A B G$, coronary artery bypass grafting; $L M$, left main; SYNTAX, Synergy between Percutaneous Coronary Intervention with Taxus and Cardiac Surgery; $N R$, not reported. *Median values. $\dagger$ Data are the same as those of Serruys and colleagues. ${ }^{12} \dagger$ Proportion of patients with ejection fraction $<50 \%$. $\S$ Proportion of patients with ejection fraction $<40 \%$. ||Including disease in ramus. 


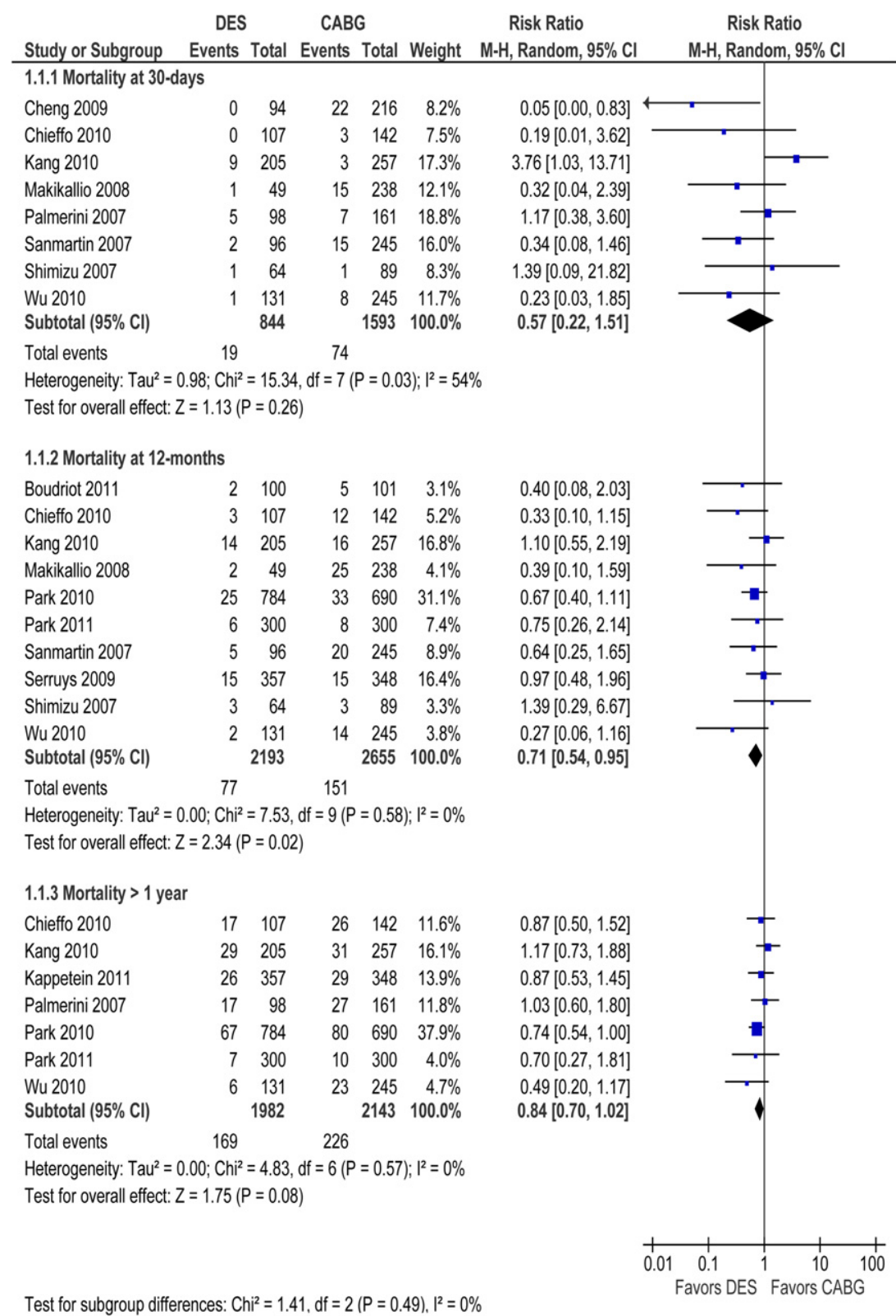

FIGURE 1. Forest plot of the RR of all-cause mortality after DES versus CABG for LMCAD. The estimate of the RR of each trial corresponds to the middle of the squares, and the horizontal line shows the $95 \%$ CI. On each line, the numbers of events as a fraction of the total number randomized are shown for both treatment groups. For each subgroup, the sum of the statistics, along with the summary RR, is represented by the middle of the solid diamonds. A test of heterogeneity between the trials within a subgroup is given below the summary statistics. $C I$, Confidence interval; $C A B G$, coronary artery bypass grafting; $D E S$, drug-eluting stent.

In addition, there was a trend toward lower all-cause mortality at follow-up beyond 12 months $(8.5 \%$ vs $10.5 \%$; RR, $0.84 ; 95 \%$ CI, $0.70-1.02 ; P=.08 ; \mathrm{I}^{2}=0 \%$ ). These results are summarized in Figure 1.

\section{Assessment of Stroke}

Nine studies reported the incidence of stroke and demonstrated a lower risk after DES compared with CABG at 30 days $(0.5 \%$ vs $3.4 \%$; RR, $0.28 ; 95 \%$ CI, $0.11-0.73$; $\left.P=.009 ; \mathrm{I}^{2}=0 \%\right), 12$ months $(0.4 \%$ vs $2.1 \%$; RR,
$0.25 ; 95 \%$ CI, $0.09-0.68 ; P=.007 ; \mathrm{I}^{2}=0 \%$ ), and follow-up beyond 12 months $(1.2 \%$ vs $3.3 \%$; RR, 0.39 ; $95 \%$ CI, $0.20-0.76 ; P=.005 ; \mathrm{I}^{2}=0 \%$ ). The definition of stroke included transient ischemic attacks in one study ${ }^{18}$ but was excluded in others. ${ }^{10,11,21,25}$ These results are summarized in Figure 2.

\section{Assessment of Myocardial Infarction}

Myocardial infarction was more likely to occur after DES compared with CABG at 30 days $(2.9 \%$ vs $1.1 \%$; 


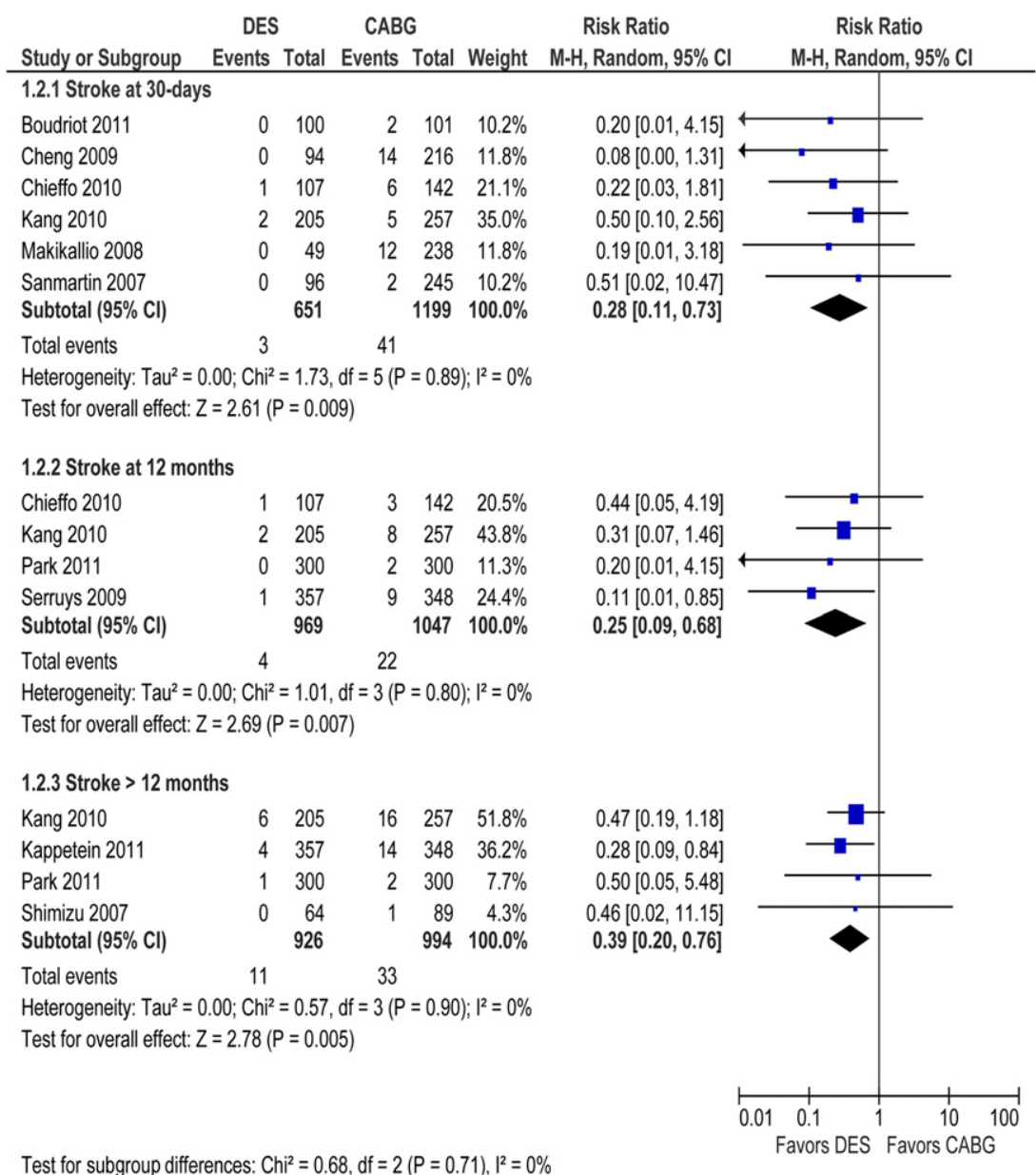

FIGURE 2. Forest plot of the RR of stroke after DES versus CABG for LMCAD. The estimate of the RR of each trial corresponds to the middle of the squares, and the horizontal line shows the $95 \%$ CI. On each line, the numbers of events as a fraction of the total number randomized are shown for both treatment groups. For each subgroup, the sum of the statistics, along with the summary RR, is represented by the middle of the solid diamonds. A test of heterogeneity between the trials within a subgroup is given below the summary statistics. $C I$, Confidence interval; $C A B G$, coronary artery bypass grafting; $D E S$, drug-eluting stent.

RR, 2.56; 95\% CI, 1.21-5.40; $P=.01 ; \mathrm{I}^{2}=43 \%$ ), but no significant difference was reported at 12 months $(2.8 \%$ vs $2.3 \%$; RR, $1.21 ; 95 \%$ CI, $\left.0.69-2.12 ; P=.51 ; \mathrm{I}^{2}=0 \%\right)$ and at follow-up beyond 12 months $(3.8 \%$ vs $2.3 \%$; RR, $1.51 ; 95 \%$ CI, 0.93-2.43; $\left.P=.09 ; \mathrm{I}^{2}=0 \%\right)$. All studies except for 2 defined postprocedural myocardial infarction as an elevation of serologic cardiac biomarkers with or without ECG changes, which is consistent with previous guidelines. ${ }^{13,14}$ Chieffo and colleagues ${ }^{18}$ and Park and colleagues ${ }^{23}$ diagnosed perioperative myocardial infarction in all patients who developed new pathologic Q-waves, with or without changes in cardiac enzymes. According to this definition, 10 of 107 patients $(9.3 \%)$ had in-hospital myocardial infarctions after DES and 37 of 142 patients (26.1\%) had myocardial infarctions after CABG in the report by Chieffo and colleagues. ${ }^{18}$ Because of the significant variation of definition in these 2 studies, outcomes of myocardial infarction and MACCE were excluded from the present meta-analysis. These results are summarized in Figure 3.

\section{Assessment of Revascularization}

The repeat revascularization rate was significantly higher after DES compared with CABG at 12 months $(11.9 \%$ vs $3.5 \%$; RR, 3.41; 95\% CI, 2.59-4.51; $P<.00001$; $\left.\mathrm{I}^{2}=42 \%\right), 24$ months $(15.0 \%$ vs $7.7 \%$; RR, $2.23 ; 95 \%$ CI, 1.61-3.09; $P<.00001 ; \mathrm{I}^{2}=0 \%$ ), and follow-up beyond 2 years $(20.8 \%$ vs $7.7 \%$; RR, 3.01; 95\% CI, 2.34-3.88; $P<.00001 ; \mathrm{I}^{2}=68 \%$ ). These results are summarized in Figure 4.

\section{Assessment of Major Adverse Cardiac and Cerebrovascular Events}

From the relevant studies identified from the current literature, MACCE was most commonly defined as a combined incidence of mortality, stroke, myocardial infarction, 


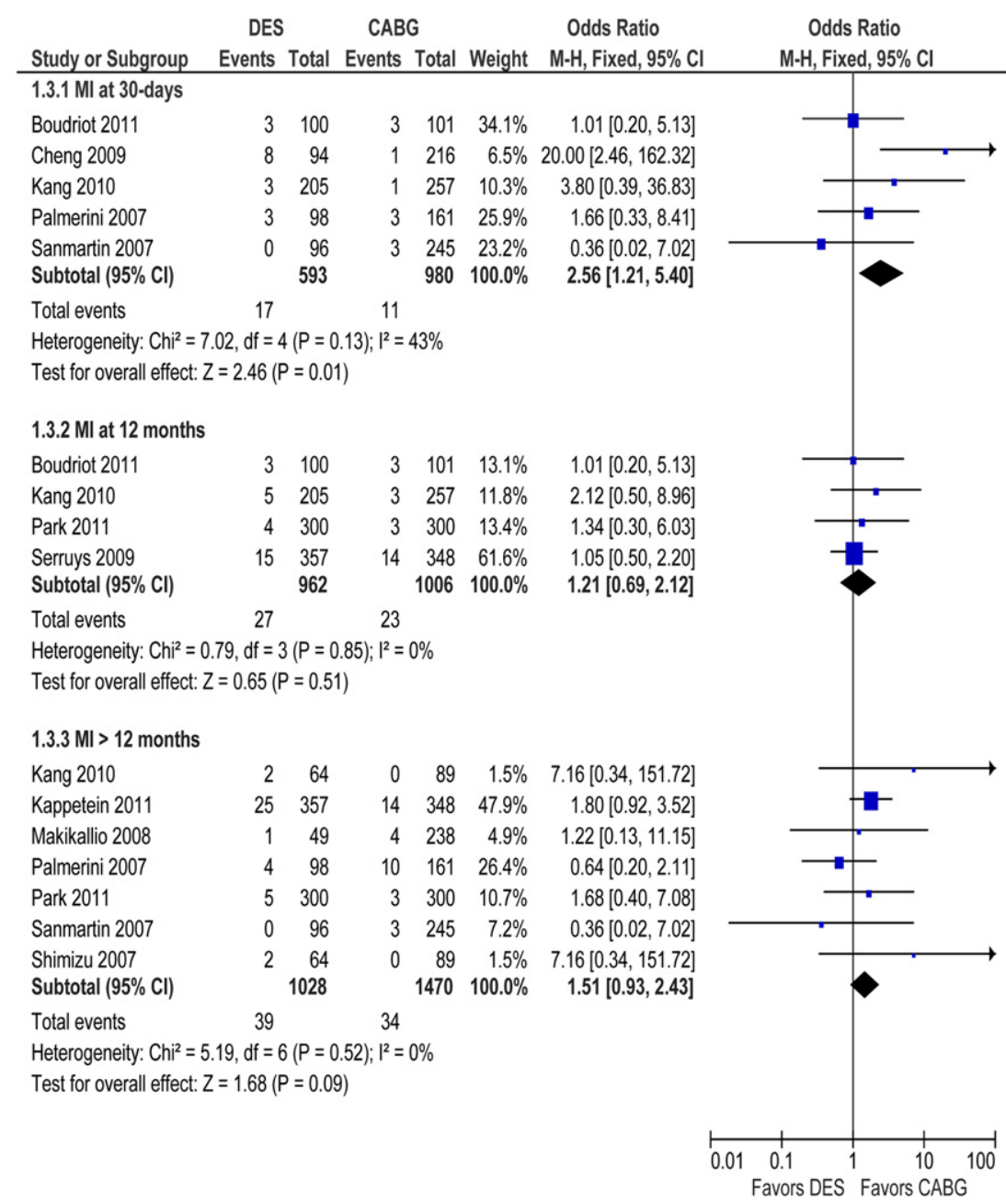

FIGURE 3. Forest plot of the RR of MI after DES versus CABG for LMCAD. The estimate of the RR of each trial corresponds to the middle of the squares, and the horizontal line shows the $95 \%$ CI. On each line, the numbers of events as a fraction of the total number randomized are shown for both treatment groups. For each subgroup, the sum of the statistics, along with the summary RR, is represented by the middle of the solid diamonds. A test of heterogeneity between the trials within a subgroup is given below the summary statistics. $C I$, Confidence interval; $C A B G$, coronary artery bypass grafting; $D E S$, drug-eluting stent.

and repeat revascularization. To assess similar end points in all studies, those studies that excluded stroke ${ }^{9}$ or repeat revascularization $^{19}$ or included repeat hospitalization ${ }^{21}$ as part of MACCE were excluded from analysis. The remaining 7 studies demonstrated a similar incidence of MACCE after DES or CABG at 30 days (3.1\% vs $5.3 \%$; RR, 0.65 ; $95 \%$ CI, $0.39-1.09 ; P=.10 ; \mathrm{I}^{2}=60 \%$ ), but a significantly higher incidence of MACCE after DES compared with CABG at 12 months $(16.4 \%$ vs $11.8 \%$; RR, 1.53 ; $95 \%$ CI, $\left.1.23-1.89 ; P=.0001 ; \mathrm{I}^{2}=18 \%\right)$ and follow-up beyond 12 months $(25.9 \%$ vs $19.5 \%$; RR, 1.57 ; $95 \%$ CI, $1.29-1.89$; $\left.P<.00001 ; \mathrm{I}^{2}=10 \%\right)$. These results are summarized in Figure 5.

\section{DISCUSSION}

Since the introduction of percutaneous revascularization techniques in the 1990s, there has been a paradigm shift toward catheterization-based treatment strategies as an alternative to $\mathrm{CABG}$ in the management of coronary artery disease. However, patients with LMCAD have traditionally been considered to have improved outcomes after surgical intervention compared with PCI. ${ }^{27}$ Recent improvements in percutaneous technology in the form of DES have reduced restenosis rates and mortality, repeat revascularization, and MACCE compared with bare metal stents. ${ }^{28}$ Despite a heightened interest in the comparative outcomes of DES versus CABG for patients with LMCAD, the choice for the optimal revascularization technique remains controversial.

In the present meta-analysis, significant heterogeneity was identified among 3 randomized-controlled trials and 9 observational studies. DES included a number of different stents, most commonly sirolimus- and paclitaxel-eluting stents. For patients who underwent CABG, off-pump 


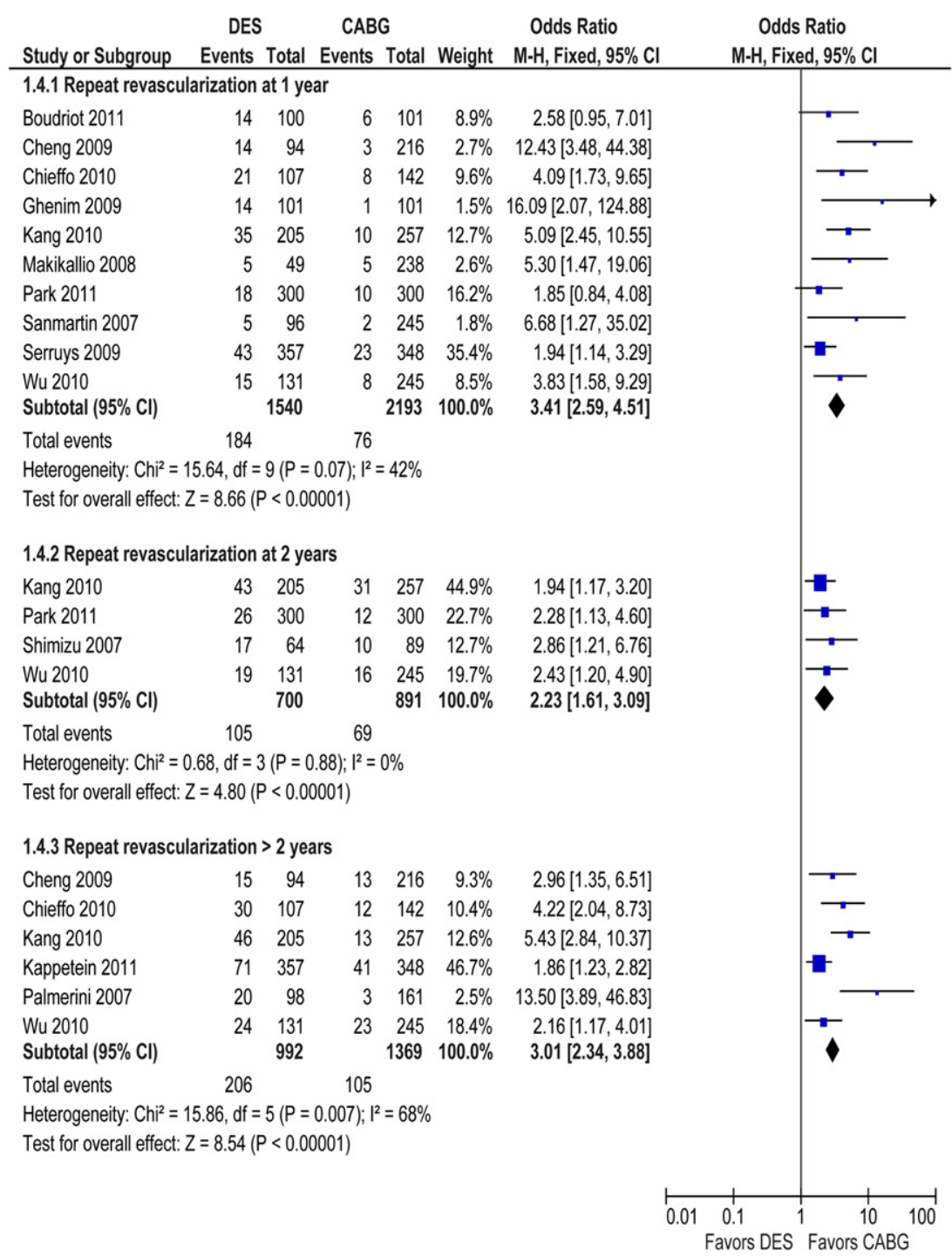

FIGURE 4. Forest plot of the RR of repeat revascularization after DES versus CABG for LMCAD. The estimate of the RR of each trial corresponds to the middle of the squares, and the horizontal line shows the $95 \% \mathrm{CI}$. On each line, the numbers of events as a fraction of the total number randomized are shown for both treatment groups. For each subgroup, the sum of the statistics, along with the summary RR, is represented by the middle of the solid diamonds. A test of heterogeneity between the trials within a subgroup is given below the summary statistics. $C I$, Confidence interval; $C A B G$, coronary artery bypass grafting; $D E S$, drug-eluting stent.

surgery was performed in $0 \%$ to $91 \%$ of cases. Patient selection criteria varied between institutions, including 1 study that only included patients who were aged 75 years or more. ${ }^{19}$ The definitions of measured end points also differed between institutions, but generally included components of MACCE, including mortality, stroke, myocardial infarction, and repeat revascularization.

Results from the selected studies in the present metaanalysis demonstrated lower all-cause mortality rates at 12 months after DES compared with CABG. Patients who underwent $\mathrm{CABG}$ were also more likely to have a stroke, whereas patients who underwent DES were more likely to require repeat revascularization. Myocardial infarction was found to be less likely after CABG at 30 days, but this difference was no longer significant at 12 months and beyond. There was a trend toward fewer MACCE after DES compared with CABG at 30 days, but this finding was reversed at 12 months and at follow-up beyond 12 months, when patients who had CABG were found to be significantly less likely to have MACCE.

Contrary to previous reports, data from the present meta-analysis demonstrated a lower all-cause mortality rate for patients who underwent DES compared with CABG at 12 months and a trend toward lower all-cause mortality beyond 1 year follow-up. ${ }^{29}$ A number of potential contributing factors may explain this unexpected finding. First, all-cause mortality rates may be due to patient 


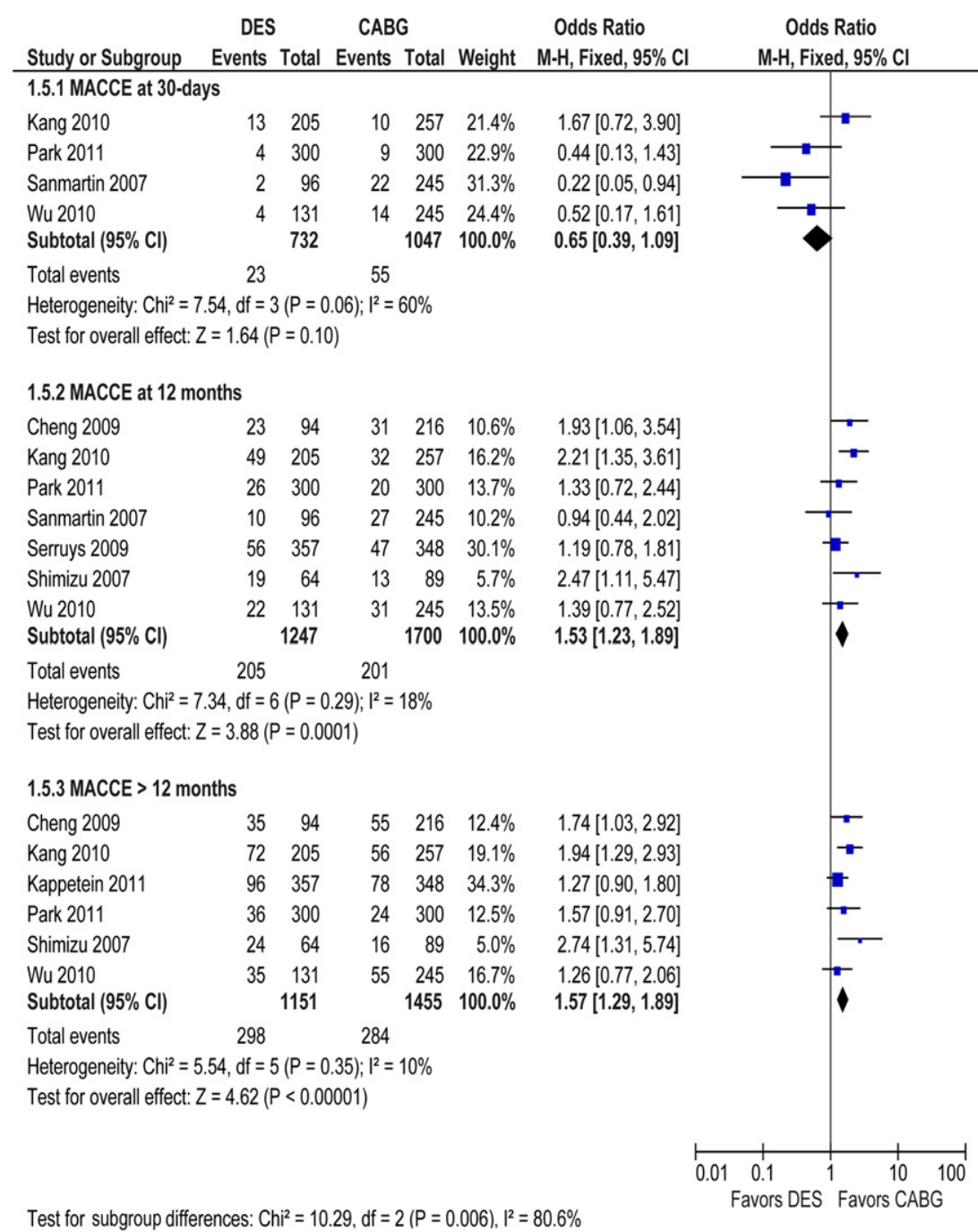

FIGURE 5. Forest plot of the RR of MACCE after DES versus CABG for LMCAD. The estimate of the RR of each trial corresponds to the middle of the squares, and the horizontal line shows the $95 \%$ CI. On each line, the numbers of events as a fraction of the total number randomized are shown for both treatment groups. For each subgroup, the sum of the statistics, along with the summary RR, is represented by the middle of the solid diamonds. A test of heterogeneity between the trials within a subgroup is given below the summary statistics. $C I$, Confidence interval; $C A B G$, coronary artery bypass grafting; $D E S$, drug-eluting stent; $M A C C E$, major adverse cardiac and cerebrovascular events.

factors unrelated to LMCAD. Indeed, when cardiacspecific mortality was examined, none of the individual studies or their accumulated results at 30-days, 12 months, and beyond 12 months were significantly different after DES compared with CABG. ${ }^{10,17,18,20}$ Second, differences in baseline characteristics and the patient selection process may have resulted in a biased patient cohort who underwent $\mathrm{CABG}$. From the data presented in Table 2, it can be seen that patients were generally more likely to present with acute coronary syndrome before CABG compared with DES. In addition, none of the individual randomized controlled trials or any of their accumulated results at 30 days, 12 months, and at follow-up beyond 12 months demonstrated any significant differences in all-cause survival. ${ }^{9-12}$
It should be acknowledged that results from the present meta-analysis were collected from a highly selected group of patients treated in tertiary referral centers, and their outcomes may not reflect the target population. LMCAD includes a wide spectrum of anatomic features that may or may not be associated with concurrent multivessel disease. Previous studies have shown that $70 \%$ to $90 \%$ of patients with LMCAD will present with multivessel coronary artery disease. ${ }^{12,30}$ From the summarized data demonstrated in Table 2, it seems that patients with LMCAD and concomitant multivessel disease may be underrepresented in the comparative studies included in the present meta-analysis. In all the observational studies, patients were more likely to undergo CABG if they were found to have LMCAD in combination with multivessel disease..$^{9,17,19,20,25,26}$ 
Furthermore, patients in the randomized controlled trials were screened before randomization and allocated to a parallel nested registry if deemed to have complex anatomic features. ${ }^{10,12}$ Although there are limited data to provide long-term outcomes for subgroups of patients with concurrent multisvessel disease, results from 2 large randomized controlled trials report a trend toward better outcomes for patients with 2- and 3-vessel disease after CABG compared with DES. It has been demonstrated that the anatomic complexity of coronary artery disease quantified by the Synergy between Percutaneous Coronary Intervention with Taxus and Cardiac Surgery (SYNTAX) score is less influential on patient outcome after CABG compared with DES. $^{31}$

The SYNTAX trial is the largest randomized controlled trial to compare DES with CABG, involving 1800 patients with previously untreated 3-vessel disease or LMCAD..$^{10,12}$ Results from the predefined subgroup of randomized patients with LMCAD who underwent DES $(\mathrm{n}=357)$ or CABG $(\mathrm{n}=348)$ indicated a similar incidence of MACCE $(15.8 \%$ vs $13.7 \%, P=.44)$ at 12 months. ${ }^{12} \mathrm{~Pa}$ tients who underwent DES were more likely to require repeat revascularization $(11.8 \%$ vs $6.5 \%, P=.02)$ but had a decreased risk of stroke $(0.3 \%$ vs $2.7 \%, P=.01)$, similar to the results of the present meta-analysis. These findings were repeated at 3-year follow-up, but there is an emerging trend toward a higher incidence of myocardial infarction $(8.9 \%$ vs $4.1 \%, P=.14)$ and MACCE $(26.8 \%$ vs $22.3 \%, P=.20$ ) for patients treated by DES compared with CABG. ${ }^{10}$ Indeed, MACCE was found to be significantly higher in patients treated by DES in the entire randomized cohort $(28.0 \%$ vs $20.2 \%, P<.001)$, and stroke was no longer significantly different at 3 years $(2.0 \%$ vs $3.4 \%, P=.07)$. Perhaps more important, it should be highlighted that only a minor proportion (1800/4337) of patients assessed for eligibility were eventually randomized in this "all-comers" trial. Of the patients who were excluded from randomization, 198 patients who underwent DES and 1077 patients who underwent CABG were included in a separate nested registry, which found higher incidences of MACCE $(20.4 \%$ vs $8.8 \%)$, mortality $(7.3 \%$ vs $2.5 \%)$, myocardial infarction $(4.2 \%$ vs $2.5 \%)$, and repeat revascularization $(12.0 \%$ vs $3.0 \%)$ for patients who were treated by DES at 12 months. The main reason for registry allocation to $\mathrm{CABG}(70.9 \%)$ was the complexity of anatomy, whereas the main reason for PCI allocation was increased comorbidity $(70.7 \%)$. Likewise, a randomized controlled trial by Boudriot and colleagues ${ }^{9}$ compared 100 patients who underwent DES with 101 patients who underwent CABG. The authors reported similar combined incidences of cardiac death, myocardial infarction, and repeat revascularization at 12 months $(19.0 \%$ vs $13.9 \%, P=.19$ for non-inferiority). However, of the 229 patients with LMCAD who were considered ineligible for randomization, a significantly lower incidence of MACCE was reported for CABG compared with DES and conservative therapy $(17.8 \%$ vs $27.5 \%$ vs $43 \%)$. Although reasons for exclusion from randomization differ between trials, it should be emphasized that results derived from patients selected for randomization in these tertiary referral centers do not necessarily represent the target population of patients diagnosed with LMCAD, especially those with more complex disease. Finally, all 3 randomized controlled trials identified from the current literature used non-inferiority tests for statistical analysis with relatively wide margins, and none of the studies were sufficiently powered for analysis of individual end points. $^{9-12}$

\section{CONCLUSIONS}

Results from the present meta-analysis found a higher incidence of MACCE for patients who underwent DES compared with CABG at 12 months and beyond. Patients were also more likely to require repeat revascularization after DES compared with CABG but were less likely to have a stroke and had a lower all-cause mortality rate at 12 months. Randomized controlled trials in the current literature seem to exclude a large proportion of patients from randomization and analysis, and patients who are deemed ineligible for randomization are more likely to undergo CABG with superior outcomes compared with PCI. Overall, current evidence suggests that $\mathrm{CABG}$ is still superior to DES for the majority of patients with LMCAD, especially for those with complex anatomy and multivessel disease at follow-up beyond 12 months. However, there is now evidence that DES may have an important clinical role for selected patients with percutaneously amenable left main disease who are poor surgical candidates. Future studies should aim to recruit larger number of patients in welldesigned randomized trials with sufficient follow-up and complete analysis of all MACCE. Specifically, 5-year follow-up data from the SYNTAX trial and the upcoming Evaluation of Xience Prime versus Coronary Artery Bypass Surgery for Effectiveness of Left Main Revascularization (EXCEL) trial $^{32}$ may offer valuable insight to long-term outcomes.

\section{References}

1. DeMots H, Rosch J, McAnulty JH, Rahimtoola SH. Left main coronary artery disease. Cardiovasc Clin. 1977;8:201-11.

2. Chaitman BR, Fisher LD, Bourassa MG, Davis K, Rogers WJ, Maynard C, et al. Effect of coronary bypass surgery on survival patterns in subsets of patients with left main coronary artery disease. Report of the Collaborative Study in Coronary Artery Surgery (CASS). Am J Cardiol. 1981;48:765-77.

3. Takaro T, Peduzzi P, Detre KM, Hultgren HN, Murphy ML, van der Bel-Kahn J, et al. Survival in subgroups of patients with left main coronary artery disease. Veterans Administration Cooperative Study of Surgery for Coronary Arterial Occlusive Disease. Circulation. 1982;66:14-22.

4. Ragosta M, Dee S, Sarembock IJ, Lipson LC, Gimple LW, Powers ER. Prevalence of unfavorable angiographic characteristics for percutaneous intervention in patients with unprotected left main coronary artery disease. Catheter Cardiovasc Interv. 2006;68:357-62. 
5. Stettler C, Wandel S, Allemann S, Kastrati A, Morice MC, Schomig A, et al. Outcomes associated with drug-eluting and bare-metal stents: a collaborative network meta-analysis. Lancet. 2007;370:937-48.

6. Kushner FG, Hand M, Smith SC Jr, King SB 3rd, Anderson JL, Antman EM, et al. 2009 focused updates: ACC/AHA guidelines for the management of patients with ST-elevation myocardial infarction (updating the 2004 guideline and 2007 focused update) and ACC/AHA/SCAI guidelines on percutaneous coronary intervention (updating the 2005 guideline and 2007 focused update): a report of the American College of Cardiology Foundation/American Heart Association Task Force on Practice Guidelines. [Erratum appears in Catheter Cardiovasc Interv. 2010;75:1143. Note: Dosage error in article text.]. Catheter Cardiovasc Interv. 2009;74:1

7. Wijns W, Kolh P, Danchin N, Di Mario C, Falk V, Folliguet T, et al. Guidelines on myocardial revascularization. Eur Heart J. 2010;31:2501-55.

8. Lee MS, Kapoor N, Jamal F, Czer L, Aragon J, Forrester J, et al. Comparison of coronary artery bypass surgery with percutaneous coronary intervention with drug-eluting stents for unprotected left main coronary artery disease. $J \mathrm{Am}$ Coll Cardiol. 2006;47:864-70.

9. Boudriot E, Thiele H, Walther T, Liebetrau C, Boeckstegers P, Pohl T, et al. Randomized comparison of percutaneous coronary intervention with sirolimuseluting stents versus coronary artery bypass grafting in unprotected left main stem stenosis. J Am Coll Cardiol. 2011;57:538-45.

10. Kappetein AP, Feldman TE, Mack MJ, Morice MC, Holmes DR, Stahle E, et al. Comparison of coronary bypass surgery with drug-eluting stenting for the treatment of left main and/or three-vessel disease: 3-year follow-up of the SYNTAX trial. Eur Heart J. 2011;32:2125-34.

11. Park S-J, Kim Y-H, Park D-W, Yun S-C, Ahn J-M, Song HG, et al. Randomized trial of stents versus bypass surgery for left main coronary artery disease. $N$ Engl J Med. 2011;364:1718-27.

12. Serruys PW, Morice M-C, Kappetein AP, Colombo A, Holmes DR, Mack MJ, et al. Percutaneous coronary intervention versus coronary-artery bypass grafting for severe coronary artery disease. $N$ Engl J Med. 2009;360:961-72.

13. Cutlip D, Windecker S, Mehran R, Boam A, Cohen D, Es GV, et al. Clinical end points in coronary stent trials: a case for standardized definitions. Circulation. 2007; 115:2344-51.

14. Thygesen K, Alpert J, White H, Jaffe A, Apple F, Galvani M, et al. Universal definition of myocardial infarction. Circulation. 2007;116:2634-53. Epub 007 Oct 19.

15. DerSimonian R, Laird N. Meta-analysis in clinical trials. Control Clin Trials. 1986; 7:177-88.

16. Higgins JP, Thompson SG. Quantifying heterogeneity in a meta-analysis. Stat Med. 2002;21:1539-58.

17. Cheng C-I, Lee F-Y, Chang J-P, Hsueh S-K, Hsieh Y-K, Fang C-Y, et al. Long-term outcomes of intervention for unprotected left main coronary artery stenosis: coronary stenting vs coronary artery bypass grafting. Circ J. 2009;73: 705-12.

18. Chieffo A, Magni V, Latib A, Maisano F, Ielasi A, Montorfano M, et al. 5-year outcomes following percutaneous coronary intervention with drug-eluting stent implantation versus coronary artery bypass graft for unprotected left main coronary artery lesions the Milan experience. JACC: Cardiovasc Interv. 2010;3: 595-601.

19. Ghenim R, Roncalli J, Tidjane AM, Bongard V, Ziani A, Boudou N, et al. Oneyear follow-up of nonrandomized comparison between coronary artery bypass grafting surgery and drug-eluting stent for the treatment of unprotected left main coronary artery disease in elderly patients (aged $>$ or $=75$ years). J Inter Cardiol. 2009;22:520-6.

20. Kang S-H, Park K-H, Choi D-J, Park KW, Chung W-Y, Lim C, et al. Coronary artery bypass grafting versus drug-eluting stent implantation for left main coronary artery disease (from a two-center registry). Am J Cardiol. 2010;105:343-51.

21. Makikallio TH, Niemela M, Kervinen K, Jokinen V, Laukkanen J, Ylitalo I, et al. Coronary angioplasty in drug eluting stent era for the treatment of unprotected left main stenosis compared to coronary artery bypass grafting. Ann Med. 2008;40:437-43

22. Palmerini T, Barlocco F, Santarelli A, Bacchi-Reggiani L, Savini C, Baldini E, et al. A comparison between coronary artery bypass grafting surgery and drug eluting stent for the treatment of unprotected left main coronary artery disease in elderly patients (aged $>$ or $=75$ years). Eur Heart J. 2007;28:2714-9.

23. Park D-W, Seung KB, Kim Y-H, Lee J-Y, Kim W-J, Kang S-J, et al. Long-term safety and efficacy of stenting versus coronary artery bypass grafting for unprotected left main coronary artery disease: 5-year results from the MAINCOMPARE (Revascularization for Unprotected Left Main Coronary Artery Stenosis: Comparison of Percutaneous Coronary Angioplasty Versus Surgical Revascularization) registry. J Am Coll Cardiol. 2010;56:117-24.

24. Sanmartin M, Baz JA, Claro R, Asorey V, Duran D, Pradas G, et al. Comparison of drug-eluting stents versus surgery for unprotected left main coronary artery disease. Am J Cardiol. 2007;100:970-3.

25. Shimizu T, Ohno T, Ando J, Fujita H, Nagai R, Motomura N, et al. Mid-term results and costs of coronary artery bypass vs drug-eluting stents for unprotected left main coronary artery disease. Circ J. 2010;74:449-55.

26. Wu X, Chen Y, Liu H, Teirstein PS, Kirtane AJ, Ge C, et al. Comparison of longterm (4-year) outcomes of patients with unprotected left main coronary artery narrowing treated with drug-eluting stents versus coronary-artery bypass grafting. Am J Cardiol. 2010;105:1728-34.

27. Antman EM, Anbe DT, Armstrong PW, Bates ER, Green LA, Hand M, et al ACC/AHA guidelines for the management of patients with ST-elevation myocardial infarction: a report of the American College of Cardiology/American Heart Association Task Force on Practice Guidelines (Committee to Revise the 1999 Guidelines for the Management of Patients with Acute Myocardial Infarction) [Erratum appears in Circulation. 2005;111:2013-4]. [Erratum appears in Circulation. 2007;115:e411]. [Erratum appears in Circulation. 2010;121:e441]. Circulation. 2004;110:31.

28. Pandya S, Kim Y, Meyers S, Davidson C, Flaherty J, Park D, et al. Drug-eluting versus bare-metal stents in unprotected left main coronary artery stenosis a metaanalysis. JACC Cardiovasc Interv. 2010;3:602-11.

29. Yan TD, Padang R, Poh C, Cao C, Wilson MK, Bannon PG, et al. Drug-eluting stents versus coronary artery bypass grafting for the treatment of coronary artery disease: a meta-analysis of randomized and nonrandomized studies. $J$ Thorac Cardiovasc Surg. 2011;141:1134-44.

30. Taggart D, Kaul S, Boden W, Ferguson TJ, Guyton R, Mack M, et al. Revascularization for unprotected left main stem coronary artery stenosis stenting or surgery. J Am Coll Cardiol. 2008;51:885-92.

31. Mohr FW, Rastan AJ, Serruys PW, Kappetein AP, Holmes DR, Pomar JL, et al. Complex coronary anatomy in coronary artery bypass graft surgery: impact of complex coronary anatomy in modern bypass surgery? Lessons learned from the SYNTAX trial after two years. J Thorac Cardiovasc Surg. 2011;141:130-40.

32. EXCEL Clinical Trial (Study NCT01205776). Available at: http://clinicaltrials. gov/ct2/show/results/NCT01205776. Accessed January 8, 2012. 